\title{
Fostering Communicative Competence and Motivation through ComunicARTE Program
}

\author{
Sonia Lara *D, María Carmen González-Torres, Sara Ibarrola-García and Ana Zúñiga \\ School of Education and Psychology, Universidad de Navarra, 31008 Pamplona, Spain; \\ mgonzalez@unav.es (M.C.G.-T.); sigarcia@unav.es (S.I.-G.); azlacruz@unav.es (A.Z.) \\ * Correspondence: slara@unav.es
}

check for updates

Citation: Lara, S.; González-Torres, M.C.; Ibarrola-García, S.; Zúñiga, A. Fostering Communicative Competence and Motivation through ComunicARTE Program. Sustainability 2021, 13, 2600. https://doi.org/10.3390/su13052600

Academic Editors: José Sánchez-Santamaría, Brenda Imelda Boroel Cervantes and David Hortigüela Alcalá

Received: 31 January 2021

Accepted: 19 February 2021

Published: 1 March 2021

Publisher's Note: MDPI stays neutral with regard to jurisdictional claims in published maps and institutional affiliations.

Copyright: (c) 2021 by the authors. Licensee MDPI, Basel, Switzerland. This article is an open access article distributed under the terms and conditions of the Creative Commons Attribution (CC BY) license (https:// creativecommons.org/licenses/by/ $4.0 /)$.
Abstract: The objective of this article is to analyse the potential of ComunicARTE, an innovative Spanish Language teaching/learning program that uses project-based learning to develop dialogic spaces which promote the communicative competence of Spanish students, together with social, emotional and motivational outcomes. Two schools have been observed with this in mind: an experimental one using this program and a control one. This is a longitudinal study with pre-and post-test data which analyses 170 children at the beginning of their fifth year and the end of their sixth year in primary school. Quantitative tests have been used to assess their communicative competence and motivational orientation in the classroom. The results obtained are discussed.

Keywords: communicative competence; reflective thinking; learning motivation; language teaching

\section{Introduction}

Over the past few decades there has been an evolution in language teaching going from an approach focused on grammatical capabilities to one more centred to achieve communicative competence [1]. What is fundamental from the communicative approach is the use of the language and not merely the systematic study of the language as knowledge. The language teacher must assign learning situations in which the student will feel the need to use the language to better understand and express him/herself. Thus, the objectives and methodology in the process of language teaching-learning must favour the development of the four language skills: listening, speaking, reading and writing [2-7]. These must all be taught and learned. However, language teaching has traditionally focused on written capabilities rather than the spoken ones. There is less pedagogical material for the teaching of the latter and its assessment is scarcely ever carried out in schools [8]. The education law in Spain currently gives great importance to the need to integrate oral language into primary classrooms. Greater visibility together with the written language is demanded (Section 4, Article 19, Annex to the LOE, Ley Orgánica de Educación, 2013).

Research on language education has drawn attention to the influence that oral language skills may have on students' learning. Specifically, it has highlighted how these improve reading comprehension [9-11]. Therefore, little by little, orality has gained ground in the teaching-learning processes. In a dialogic space $[12,13]$ the quality of the relationships and interactions allows for the opening-up, broadening and deepening of knowledge. In this framework the students will be able to develop processes and strategies of the comprehension and oral-expression capacities and use of them to favour in-depth learning of the different subjects [14].

Recently, the role of dialogue within feedback processes among equals has come to light [15]. Ajjawi and Boud, call for reconceptualising feedback as a dialogic and relational activity. When a dialogic opportunity is offered and the students participate, they tend to focus more on the content and arguments on the commentaries offered or received. Dialogue activates cognitive higher-level processes such as the application of criteria, the diagnosis of problems or suggested solutions. Dialogue on written commentaries-receive 
and give feedback - allows classmates the exchange of opinions, negotiation on meanings and offers greater efficiency of learning. The individual who receives feedback, by interacting with peers and teachers, gains additional knowledge on the perceptions of the quality or precision of his/her work [15]. Then more in-depth self-reflection, motivation and the capacity to manage one's emotions constructively can be promoted in verbal interaction.

For this approach to the development of communicative competence to work, the guidance of the teacher is very important. The establishment of a trusting atmosphere and the tone in which feedback is shared in the classroom are critical points.

Several years ago a language teacher's group developed an interactive program for the learning and teaching of Spanish Language and Literature, carried out on an iPad [16-20] and called ComunicARTE. The proposal is based on the communicative approach, emphasising on the encouragement of real dialogic situations and addresses grammar, syntax and work on the different types of text in significant didactic context. This Program uses the iPad for fifth and sixth grades of Primary school, and paper for the initial primary grades.

ComunicCarte is a proposal of teaching-learning of language and literature through comprehension projects (https:/ / www.polygoneducation.com/productos/comunicarte/). Through comprehension projects and the integration of various methodologies (based on cooperative learning and culture of thought, mainly) the students develop their communicative competence, investigate the language system, practice the production of written, oral and graphic texts. They also share them in the social context of the school.

The program has been developed for 4 th 5 th, 6 th primary school and for 3 secondary school courses. Its materials include: 3 student projects for each course; a student notebook with thinking routines to fill out on paper and be displayed on the classroom walls to make thinking visible; a teacher's guide and presentations of projects and language and literature contents. More information about this program can be found in the Appendix A.

In this study, which is part of a larger research project, we will examine whether the use of ComunicARTE improves language skills, particularly oral skills and intrinsic motivation on task [21,22].

\section{Methodology}

The setting for our research is two state-funded independent schools in the city of Pamplona (Spain) with the same Economic, Social and Cultural Status (ESCS) according to the data of the Department of Education of the Government of Navarra, more specifically Primary 5th and 6th grades (9-11 years old). The experimental school is a single-sex education centre with five groups (two for girls and three for boys in total), which uses the program to teach Spanish Language, ComunicARTE. The control school is mixed and has two groups; it uses a methodology carrying out the activities in the Spanish Language textbook. The research was carried out during the academic years 2016-2017 and 2017-2018.

The design of this study corresponds to a mixed methodology combining qualitative and quantitative data. The design aims to have a broader range, depth and diversity, together with interpretive wealth and comprehension corresponding to the object of research. The study has a two-year quasi-experimental longitudinal design with a pre- and post-test assessment of five experimental school classes in the control school. The data were gathered on several occasions, at the beginning of the academic year for Primary 5 2016-2017 (October) and the end of the academic year 2017-2018 (May); there was, then, a period of 19 months between the pre-test and post-test assessments. The sampling through which the participating teaching staff and student body were accessed was a non-probabilistic sample of convenience. The informed consent of the managers of the two schools, of the teachers and the students' parents was requested. The study has the approval of the Ethics Committee of the University of Navarra. 


\subsection{Research Questions}

The objective of this research is to analyse whether the dialogic strategies used in ComunicARTE have an effect on the development of the communicative competence of Primary 5th and 6th grade's students, particularly on orality, and on variables of intrinsic motivational orientation.

The research questions were:

(1) How do the dialogic strategies proposed in ComunicARTE affect the development of communicative competencies (writing, speaking, listening and reading) and motivation, taking into account how prior performance and gender moderate this effect?

(2) Do the experimental groups and the control group, taking into account how prior performance and gender moderate this effect, show differences in the relationship between development of communicative competencies (writing, speaking, listening and reading) and motivation?

\subsection{Sample Description}

The sample was originally made up of 182 students. Those diagnosed with special education needs, those without parental authorization and those who left the schools were eliminated from the statistical analyses. The resulting sample was 170 students; a total of 70 girls and 100 boys. Table 1 shows the distribution of the students from the experimental school and the control school. The students were assigned an alphanumeric identifier in order to match up the data from the questionnaires throughout the two academic years. We are grateful for the collaboration of the eleven Primary 5 and Year 6 Spanish Language teachers (two of whom worked in both years). The mean age of the teachers was 36.6 $(\mathrm{SD}=8.8)$ and $63.6 \%$ were women.

Table 1. Pupil distribution in the class groups in the experimental and control schools.

\begin{tabular}{cccccccccccccc}
\hline \multicolumn{1}{c}{ Experimental School } \\
\hline \multicolumn{1}{c}{ G.1 } & G.2 & G.3 & G.4 & G.5 & Total & $\%$ & G.6 & G.7 & Total & $\%$ & Total & $\%$ \\
\hline Girl & 21 & 21 & & & & 42 & 36 & 12 & 16 & 28 & 54 & 70 & 58 \\
Boy & & & 26 & 23 & 27 & 76 & 64 & 14 & 10 & 24 & 46 & 100 & 41 \\
\hline Total & 21 & 21 & 26 & 23 & 27 & 118 & 100 & 26 & 26 & 52 & 100 & 170 & 100 \\
\hline
\end{tabular}

For reasons outside the control of the researchers, in some groups the distribution of Primary 6 students varied from that of Primary 5. In the experimental school, only groups 1 and 2 maintained the same student distribution, in contrast groups 3, 4 and 5 were modified; the students of these three classes were mixed, bringing about a new student distribution in the classes of Primary 6. In the control school, the Primary 6 groups were divided into smaller groups for the Language classes (a step taken by the school in order to offer more individualized attention to the students). Despite these changes, which undoubtedly affected the original conditions of the classes, as the students had been identified from the beginning, the statistical analyses were carried out matching the pre-test and post-test data.

\subsection{Measurement Tools}

\subsubsection{Standardised Tests Which Assess Reading and Writing Processes}

In order to assess the dependent variable, we have used quantitative measurement scales which are a benchmark in Spanish in the evaluation of processes of reading and writing. These tests are based on the findings that cognitive psychology has accumulated regarding the processes involved in writing and reading. On the basis of this knowledge, the objective of these sets is to detect problems through assessment of the aspects which make up the writing and reading system, from the most complex such as the planification of ideas, to the simplest such as writing and pronunciation of syllables. These tests were designed to obtain information on the capacities of the students. 
The following tests have been selected:

- $\quad$ PROESC. Evaluación de los procesos de escritura (Assessment of writing processes) [23]. The test for planning narrative texts by means of writing a story was used, evaluating both the contents and the coherence-style. Group publication. The maximum score is 10 points. These stories were corrected by one person in order to maintain identical criteria and the same level of reliability. This test presents a Cronbach reliability coefficient of 0.82.;

- PROLEC-R. Batería de Evaluación de los Procesos Lectores, Revisada (Set for Assessment of Reading Processes, Revised) [24]. The Oral Comprehension test (individual application) was used and consists of the reading of two short texts and eight questions by the researcher which are answered orally by the student. In this way there is no interference with either the reading or the writing in the student's answers. The maximum score is eight points. These stories were corrected by one person in order to maintain identical criteria and the same level of reliability. This test presents a Cronbach reliability coefficient of 0.67 ;

- PROLEC-SE. Batería de Evaluación de los procesos Lectores en Secundaria y Bachillerato (Set for Assessment of Reading Processes at Secondary and Baccalaureate Levels) [25]. This test is weighted for children from Primary Years 5 and 6 up to the end of the baccalaureate. The Text Comprehension test was used and was applied collectively. The students read a text and respond to 10 questions for each two. The maximum score is 20 points (half of which correspond to literal responses and half to inferential responses). This test presents a Cronbach reliability coefficient of 0.80 .

\subsubsection{Competence Tests Designed Ad-Hoc to Assess Language Skills}

Ad-hoc tests were designed similar to regional, national and international assessment models (the diagnostic assessments of the Department of Education of the Government of Navarra; the tests of the Spanish Ministry of Education, Culture and Sport for the national assessment of the communicative competence of Primary 3 and 4 students; and the sample Linguistic Communication PISA for Primary 4). With all these data and considering the Spanish syllabus established for Primary 5, tests were developed to evaluate oral and written comprehension and oral and written expression.

Oral and written comprehension.

- Oral comprehension was assessed by means of two audio clips: an interview-an expository text-followed by seven questions, and a recording of an informative descriptive text on the kangaroo followed by six questions. The 13 questions require closed and semi-constructed answers, of middle and low difficulty. The cognitive processes assessed referred to the finding and obtaining of information, integration and interpretation, and reflection and assessment. The maximum score is 13 points. Collective application. This test offers a reliability coefficient of 0.51 ;

- Written comprehension was assessed by means of two reading tests: a narrative text (story) and 10 questions; and argumentative text and seven questions. The questions are of low, middle and high difficulty. The answers are closed, open and semi-constructed. The cognitive processes are finding and obtaining information, integration and interpretation, and reflection and assessment. The maximum score is 17 points. Collective application. This test offers a reliability coefficient of 0.68 .

Oral and written expression.

- Oral expression was assessed by showing the student a picture of a fairground he/she must look at for $30 \mathrm{~s}$. Four questions are asked and each must be answered orally in two ways: descriptive («Describe what you see in the picture») and narrative («tell a story based on what you see in this picture»). The cognitive processes involved are coherence, cohesion, appropriateness and fluency. Individual application. The test was applied by one researcher who used a rubric in order to score these points so as 
to maintain identical criteria for assessment and thus favours good reliability. This test offers a reliability coefficient of 0.77 ;

- Written expression was assessed by means of two activities: the writing of an expositiveargumentative text which requires the student to express opinions, reflections and well-argued assessment in writing; to make a critical analysis of the information presented through statistical graphs; to express his/her ideas clearly using appropriate linguistic tools, proper syntax and appropriate vocabulary, and to present the text clearly and neatly; and the production of instructions for a trip by underground which requires the writing of an instructional text. Both activities make use of the cognitive processes of coherence, cohesion, appropriateness and presentation. The application is collective. This test is corrected by one person and offers a reliability coefficient of 0.84 .

\subsubsection{Motivation Questionnaire}

The Scale of Intrinsic versus Extrinsic Orientation in the Classroom [21] was used, in the version adapted and validated for Spain [26]. It was developed in the English-speaking area and has a great theoretical and empirical base. It is considered a clear exponent of progress in the assessment of student motivation [27], and is valuable for greater knowledge about school performance.

Based on the conceptual framework of White, Harter designed a scale which specifies both the components that define an intrinsic orientation and those that refer to the opposite extreme [21,28]. It assesses the following factors: (a) Preference for Challenge versus Preference for Easy Work, (b) Curiosity and Interest versus Pleasing the Teacher, (c) Independence Mastery versus Dependence on Teacher, (d) Independent Judgment versus Dependence on the Teacher's Judgment, (e) Internal Criteria of Success and Failure versus External Criteria. A high score in each of the subscales reflects the existence of intrinsic motivational orientation and a low score indicates extrinsic motivational orientation. The first three subscales are motivational in as much as they refer to what the children want and like to do and what they prefer and may be an Intrinsic Mastery Motivation. The other two subscales assess more cognitive and evaluative factors, in that they refer to the basis for the students' judgments and why they make decisions regarding their school work; these may be combined into a variable called Autonomous Judgment.

\subsection{Data Analysis}

The statistical analyses were carried out using the program STATA v.14.1. In order to discover the existence of the effect of the intra group pre/post-test treatment, T-test (parametric) or Wilcoxon (nonparametric) were used for related samples, in accordance with the Shapiro-Wilk W test for normal data, depending on the results. The size of the effect was calculated with the $\mathrm{d}$ Cohen for related samples.

In order to find the differential effect of ComunicARTE compared to the control group methodology, a multiple linear regression was used where two binary variables were included as regressors which indicate their belonging to the experimental group and to that to which the observation corresponds after treatment, together with the interaction between these two variables. So, a difference-in-difference identification strategy was adopted, where the coefficient of the interaction may be interpreted as the differential effect of ComunicARTE on the experimental group. In addition, the prior and gender performance effects were controlled. Thus the coefficients of the following model

$$
y_{i}=\beta_{0}+\beta_{1} \text { Exper }_{i}+\beta_{2} \text { POST }_{i}+\beta_{3} \text { POST }_{i} \times \text { Exper }_{i}+\beta_{4} \text { Lan }_{i}+\beta_{5} \text { Lan }_{i}+\beta_{6} \text { Sex }_{i}+\varepsilon_{i}
$$

were estimated by ordinary least squares, where $y_{i}$ is the dependent variable; Exper $r_{i}$ is a dummy that takes on value 1 in observations of the experimental groups $(1,2,3,4$ and 5), and 0 on the contrary (control groups 6 and 7); $P O S T_{i}$ is a dummy that takes value 1 if the observation corresponds to post treatment; $\operatorname{Lan}_{i_{i}}$ and $\operatorname{Lan}_{i}$ corresponds to the average 
grade at the end of Year 5 and 6 in the language subject; and sex $i$ takes 1 for girls, and 0 for boys.

It was decided to control the effects of prior performance on language (Years 4 and 5 final grades) because it is a good indicator of later performance. In the same way, the effects of the sex variable were controlled as it has a significant influence on the better performance of girls in the development of communicative competence. The PIRLS Program (OCDE), which assesses Language at Primary 4th, highlighted the fact that girls present a higher performance in reading than boys and that this advantage was the same, on average, for all participating countries.

Finally, we must point out that in order to standardise the interpretation of results, all scores were normalised in such a way that the minimum is 0 and the maximum is 1 . This facilitates the comparison of the results between tests and the interpretation of the coefficients in the linear regression carried out, maybe standardised.

\section{Results}

\subsection{Oral Comprehension}

In accordance with the Prolec-R norms, for the oral comprehension test, at the beginning of Primary 5 and end of Primary 6 all of the groups present a direct score which is within the normal development for their age. Significant intragroup and size differences of the mean effect are only found-after the assessments throughout the two years-in a positive way in the experimental groups \#4 $(\mathrm{t}(18)=3.49, p=0.0026, \mathrm{~d}$ Cohen $=0.80)$ y \#5 $(\mathrm{t}(21)=4.36, p=0.0003, \mathrm{~d}$ Cohen $=0.93)$ and in a negative way in the control group \#7 $(\mathrm{t}(24)$ $=-3.4123, p=0.0023, \mathrm{~d}$ Cohen $=-0.68)$. See Figure 1.

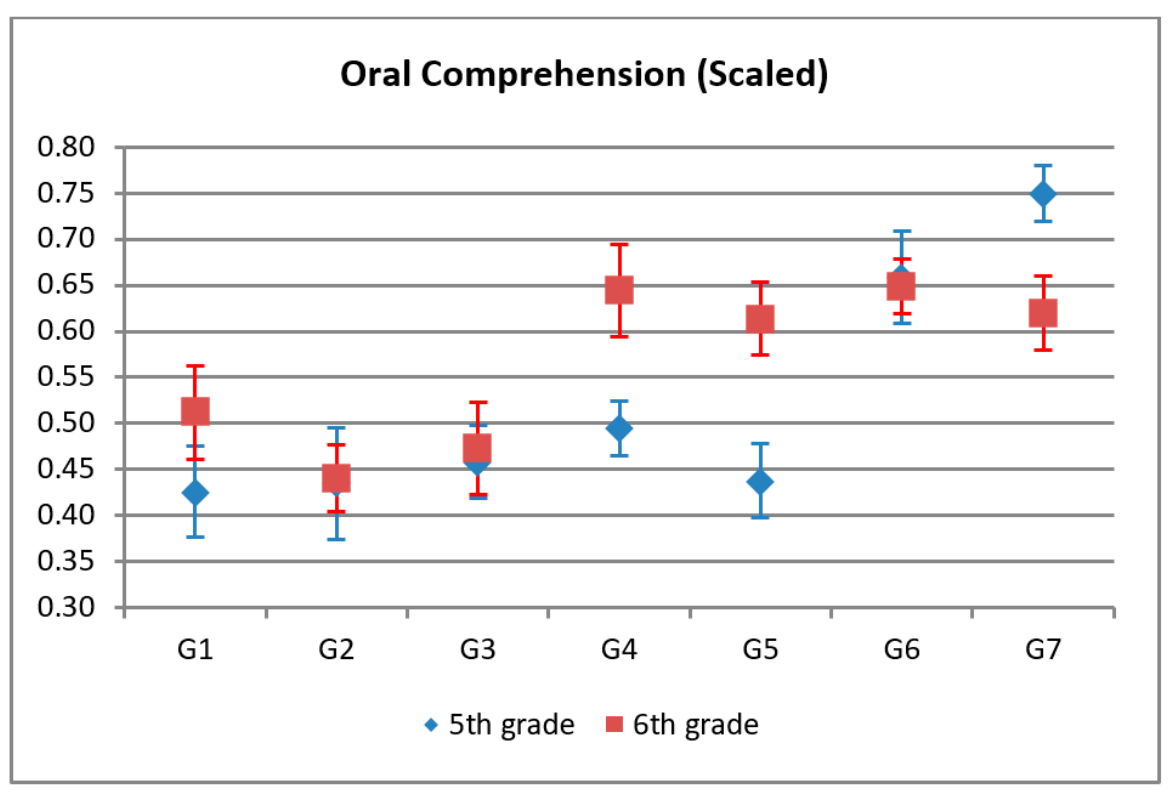

Figure 1. Means and typical error in oral comprehension (scaled).

In the case of the data obtained with the set carried out ad hoc, the results of the different groups have been more homogeneous. We have found large size effects and significant positive intragroup differences in all of them (group $1, \mathrm{Z}=3.558, p<0.0004$, $\mathrm{d}$ Cohen $=1.06$; group $2, \mathrm{Z}=2.616, p<0.0089, \mathrm{~d}$ Cohen $=0.64$; group $3, \mathrm{Z}=3.840, p<0.0001$, $\mathrm{d}$ Cohen $=1.05$; group $4, Z=3.836, p<0.0001$, $\mathrm{d}$ Cohen $=1.20$; group $5, Z=4.110, p<0.0000$, $\mathrm{d}$ Cohen $=1.13$; group $6, \mathrm{Z}=3.720, p<0.0002$, $\mathrm{d}$ Cohen $=1.17$; group $6, \mathrm{Z}=3.600, p<0.0003$, $\mathrm{d}$ Cohen $=100$ ). See Figure 2 . 


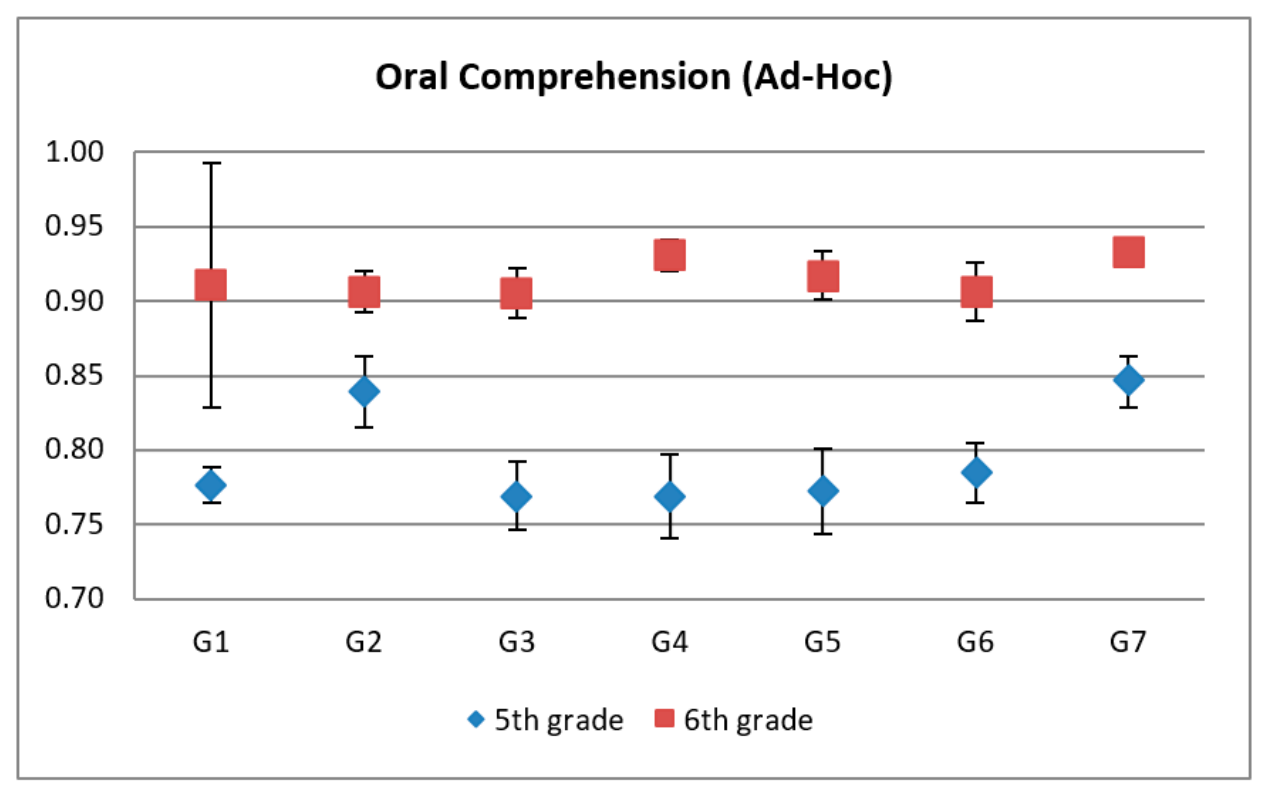

Figure 2. Means and typical error in oral comprehension (ad-hoc).

By estimating the multiple linear regression of oral comprehension (scaled and ad hoc) on the interaction of the effect of belonging to the experimental group and to the preand post-test scores, and by controlling the influence of prior performance and sex, we found that (see Appendix B):

- In the case of oral comprehension (scaled) the intervention has a positive effect on the improvement of oral comprehension (quantitative scale). We find that the estimated coefficient of the interaction between Exper and POST to be $\beta 3=0.16, t(313)=3.25$, $p<0.001$, which is statistically significant and is interpreted as evidence of the existence of a positive differential effect on the experimental group. The R2 value was 0.20 .

- In the case of oral comprehension (ad-hoc) the intervention has a positive effect on the improvement of oral comprehension. We find that the estimated coefficient of the interaction between Exper and POST to be $\beta 3=0.02, \mathrm{t}(318)=1.12, p=0.26$, which is not statistically significant and is interpreted as lack of evidence for a positive differential effect on the experimental group, although there is a certain tendency towards improvement. The R2 value was 0.39 .

\subsection{Written Comprehension}

All of the students showed a considerable improvement. In all the groups the difference between the pre-and post-test (scaled written comprehension) is significant with a large effect size (group 1, $\mathrm{t}(18)=4.6889, p=0.0002, \mathrm{~d}$ Cohen $=1.08$; group 2, $\mathrm{t}(17)=5.4251$, $p=0.0000, \mathrm{~d}$ Cohen $=1.28$; group $3, \mathrm{t}(24)=4.6203, p=0.0000, \mathrm{~d}$ Cohen $=0.92$; group 4 , $\mathrm{t}(20)=5.8387, p=0.0000, \mathrm{~d}$ Cohen $=1.27$; group $5, \mathrm{t}(22)=4.8298, p=0.0000, \mathrm{~d}$ Cohen $=1.01 ;$ group $6, \mathrm{t}(21)=5.2301, p=0.0000, \mathrm{~d}$ Cohen $=1-12$; group $7, \mathrm{t}(24)=8.8354, p=0.0000$, $\mathrm{d}$ Cohen $=1.77)$. See Figure 3. The results are similar in the ad-hoc test. All of the groups show a considerable improvement which results in significant differences in all the groups with a large effect size (group $1, Z=3.608, p=0.0003$, $d$ Cohen $=1.33$; group 2, $Z=3.807$, $p=0.0001, \mathrm{~d}$ Cohen $=1.43$; group $3, \mathrm{Z}=3.910, p=0.0001, \mathrm{~d}$ Cohen $=1.06$; group $4, \mathrm{Z}=2.899$, $p=0.0037, \mathrm{~d}$ Cohen $=0,85$; group $5, Z=4.299, p=0.0000, \mathrm{~d}$ Cohen $=1.57$; group $6, \mathrm{Z}=3.365$, $p=0.0008, \mathrm{~d}$ Cohen $=1.01$; group $7, \mathrm{Z}=3.980, p=0.0001, \mathrm{~d}$ Cohen $=1.36$ ). See Figure 4. 


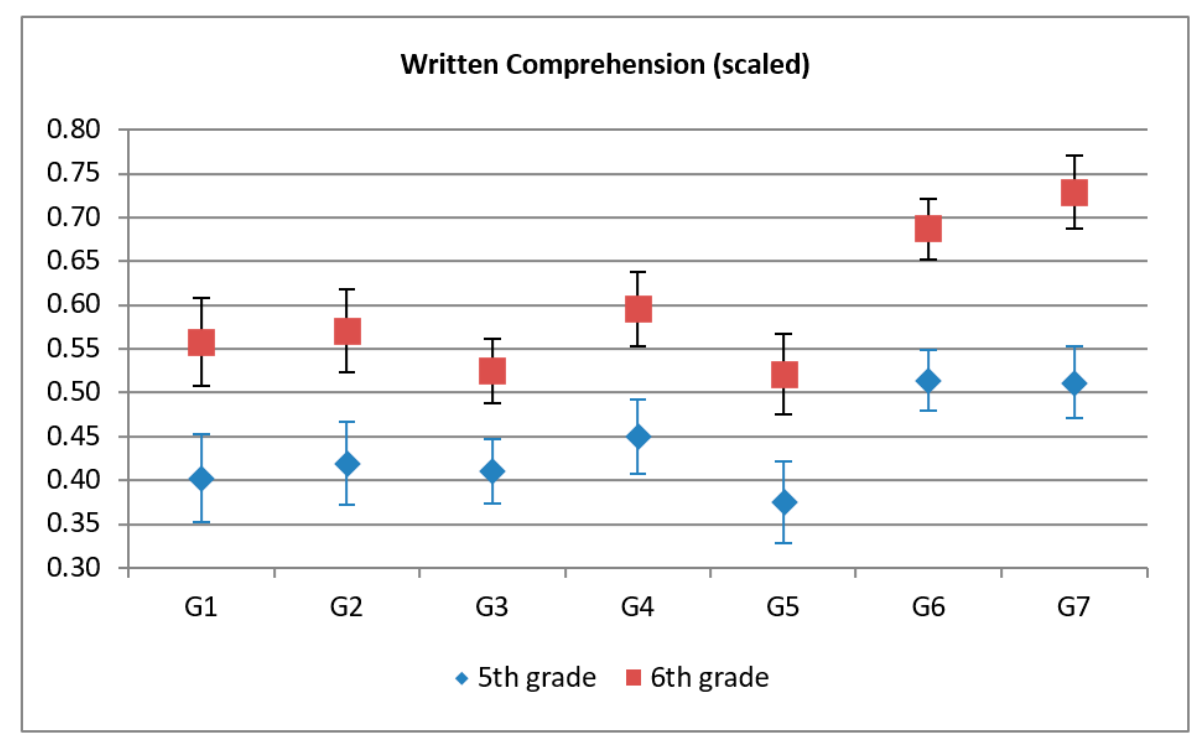

Figure 3. Means and typical error in written comprehension (scaled).

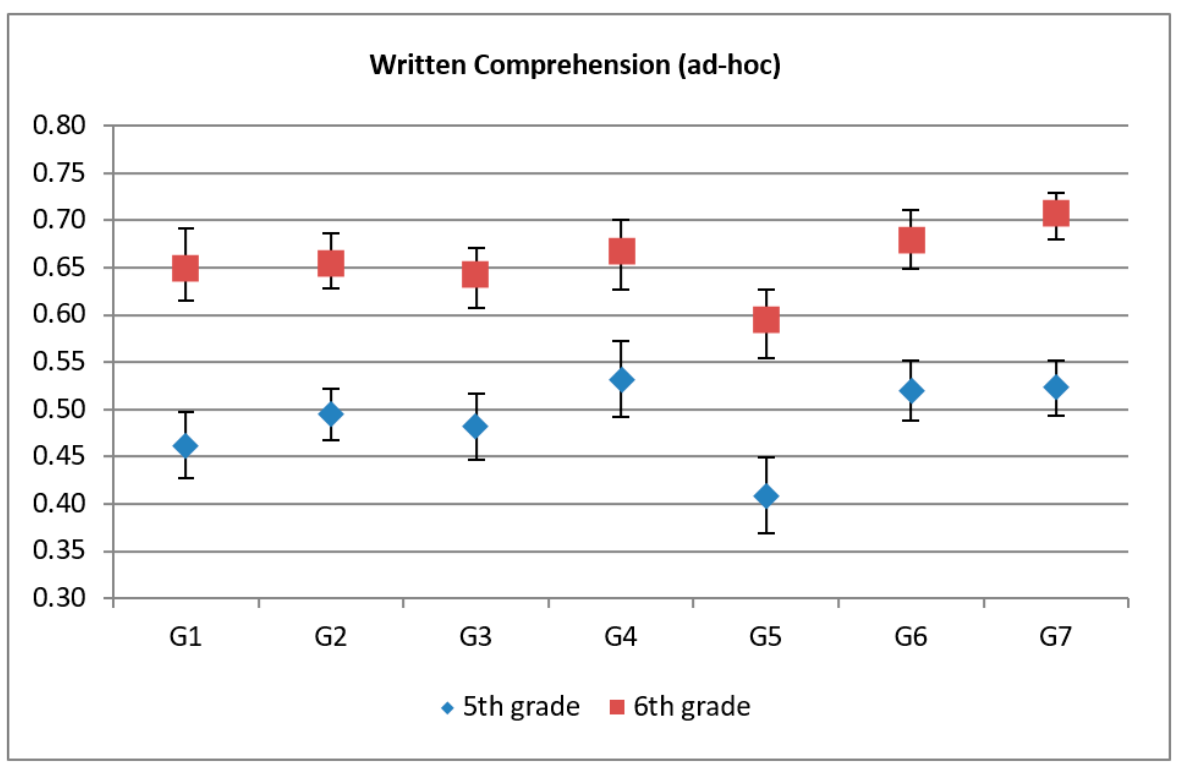

Figure 4. Means and typical error in written comprehension (ad-hoc).

Estimating the multiple linear regression for written comprehension (scaled and adhoc) on the interaction of the effect of belonging to the experimental group and the preand post-test scores, controlling the influence of prior performance and sex we find that:

- For the scaled written comprehension we find the estimated coefficient of interaction between Exper and POST to be $\beta 3=-0.05, \mathrm{t}(315)=-1.28, p=0.20$ and not statistically significant, which may not be interpreted as evidence of the existence of a negative differential effect on the experimental group, although there is a tendency for the control group to perform a little better. The R2 value was 0.41 .

- For the ad-hoc written comprehension we find also that the estimated coefficient of interaction between Exper and POST to be $\beta 3=-0.008, \mathrm{t}(318)=-0.27, p=0.78$ and not statistically significant, which may not be interpreted as evidence of the existence of a negative differential effect on the experimental group, although there is a tendency for the control group to perform a little better. The R2 value was 0.47 . 


\subsection{Written Expression}

We must not forget that the assessments of scaled and ad hoc written expression evaluate different skills. The ad-hoc test assesses the writing of a narrative text (writing a story) and the ad-hoc test assesses the writing of argumentative and instructive texts. In this case the results are not as uniform as in the previous data.

In the scaled assessments, only the control groups improve significantly with a large and middle size effect $6(\mathrm{t}(24)=3.8402, p=0.0008, \mathrm{~d}$ Cohen $=0.77)$ y $7(\mathrm{t}(24)=5.0106$, $p=0.0000$. D Cohen $=1.00)$, and the experimental group $3(t(24)=-2.5298, p=0.0184$, $\mathrm{d}$ Cohen $=-0.51$ ) deteriorates significantly, with a middle size effect; see Figure 5. In the ad-hoc mean, on the contrary, no significant intragroup differences are found between the pre-test and post-test means; see Figure 6.

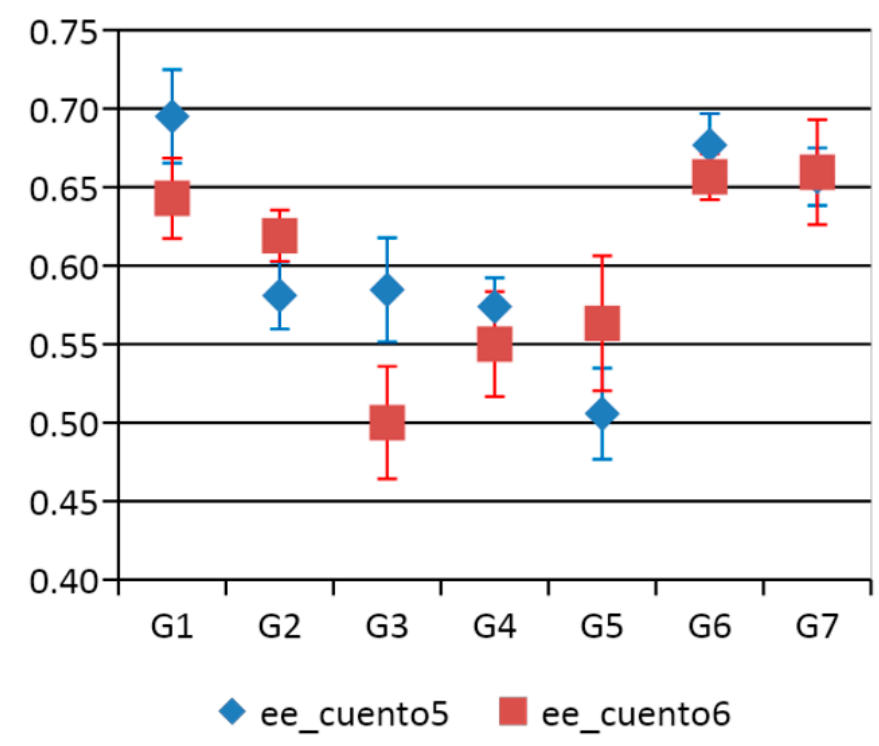

Figure 5. Means and typical error in oral expression (scaled).

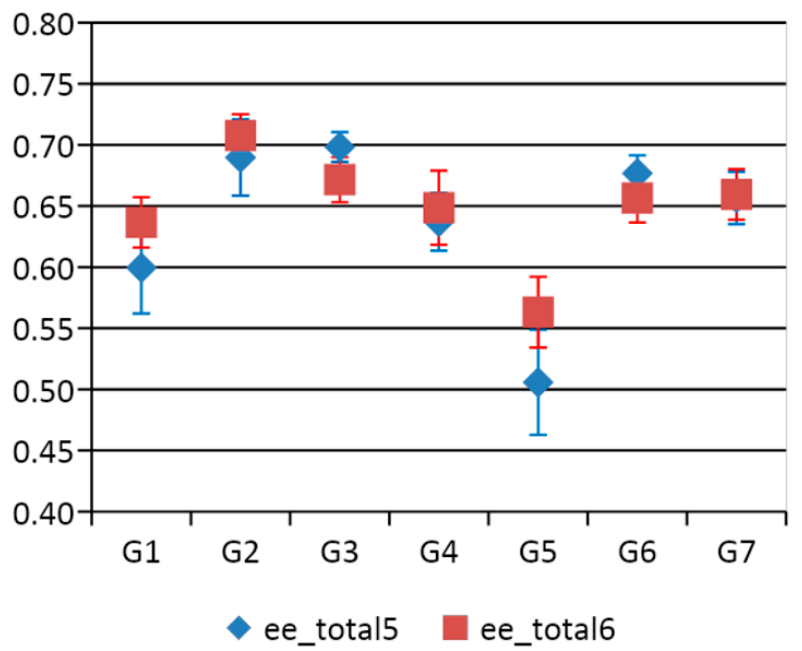

Figure 6. Means and typical error in written expression (scaled).

Estimating the multiple linear regression for written expression (scaled and ad hoc) on the interaction of the effect of belonging to the experimental group and the pre- and post-test scores, controlling the influence of prior performance (final grades Primary 5 and 6) and sex we find that: 
- For the scaled written expression: the treatment has a negative effect on the writing of a story. We find the estimated coefficient of interaction between Exper and POST to be $\beta 3=-0.17, \mathrm{t}(319)=-5.67, p<0.000$ and statistically significant, which may be interpreted as evidence of the existence of a negative differential effect on the experimental group. The R2 value was 0.25 .

- For the ad-hoc written expression: the treatment has a positive effect on the writing of argumentative and instructive texts. We find the estimated coefficient of interaction between Exper and POST to be $\beta 3=0.02, \mathrm{t}(317)=1.08, p=0.28$, but not statistically significant, which does not allow its interpretation as evidence of the existence of a positive differential effect on the experimental group, although there is a tendency towards a positive effect in the experimental group. The R2 value was 0.25 .

\subsection{Oral Expression}

The data for ad-hoc oral expression show that there is an improvement in all the groups, although the intragroup differences are only significant in experimental group 2 $(\mathrm{t}(22)=2.7126, p=0.0127, \mathrm{~d}$ Cohen $=0.57)$ and control group $7(\mathrm{t}(22)=2.5171, p=0.0196$, $\mathrm{d}$ Cohen $=0.52)$ with a middle size effect; see Figure 7.

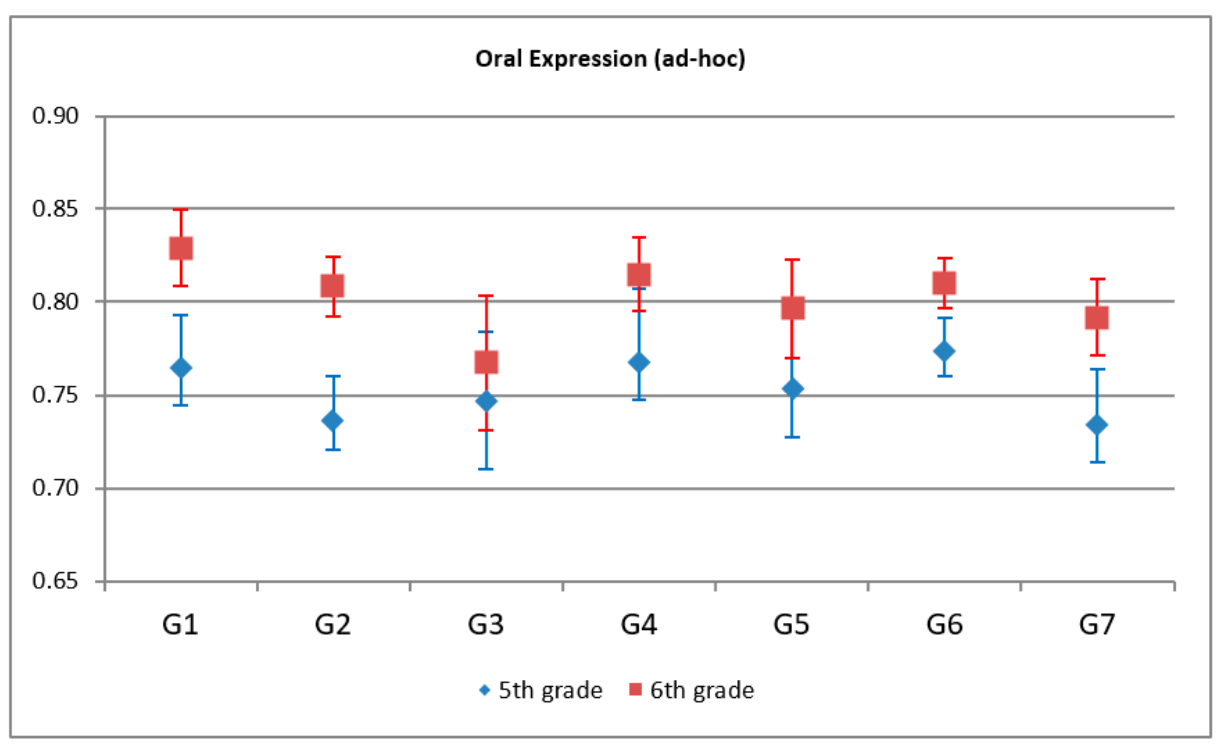

Figure 7. Means and typical error in oral expression (ad-hoc).

For the ad-hoc oral expression we find the estimated coefficient of interaction between Exper and POST to be $\beta 3=-0.0008, \mathrm{t}(326)=0.02, p=0.98$ and not statistically significant, which does not allow its interpretation as evidence of the existence of a negative differential effect on the experimental group. The $\mathrm{R} 2$ value was 0.04 . If we enlarge a little (see Appendix B) on the factors which make up this measurement (fluency, presentation, cohesion and coherence), we find different effects, none of which are significant but are an indication of a tendency. There appears to be a positive effect among the experimental group both in fluency and discourse coherence, but a negative effect is shown in the cohesion factor.

\subsection{Motivational Aspects}

For the motivation variable (see Table 2), the treatment has a positive effect on the development of independent judgment. We find the estimated interaction coefficient between Exper and POST to be $\beta 3=0.09, \mathrm{t}(311)=1.90, p=0.05$, and statistically significant, which may be interpreted as evidence of a positive differential effect in the experimental group. The R2 value was 0.03. In the remaining factors measured by the Harter Scale (1980), statistically significant coefficients are not found. 
Table 2. Summary of interaction regression coefficients between POST and Exper (motivation) in accordance with the model established: $y_{i}=\beta_{0}+\beta_{1}$ Exper $_{i}+\beta_{2}$ POST $_{i}+\beta_{3}$ POST $_{i} \times$ Exper $_{i}+\beta_{4}$ Lan $_{i}+\beta_{5}$ Lan $_{i}+\beta_{6}$ Sex $_{i}+\varepsilon_{i}$.

\begin{tabular}{|c|c|c|c|c|c|c|c|}
\hline \multicolumn{2}{|c|}{ Coef $\beta_{3}$ POST $_{i} \times$ Exper $_{i}$} & \multicolumn{6}{|c|}{ Model } \\
\hline 11 Post $\times$ Exper & & Std. Err. & $t(g l)$ & $p>t$ & R-Squared & F & $p>\mathrm{F}$ \\
\hline $\begin{array}{l}\text { Challenge vs. Preference } \\
\text { for Easy Work }\end{array}$ & -0.012 & 0.053 & $-1.22(310)$ & 0.82 & 0.046 & $F(6,304)=2.45$ & 0.0250 * \\
\hline $\begin{array}{l}\text { Curiosity and interest vs. } \\
\text { Pleasing the teacher }\end{array}$ & 0.004 & 0.05 & $0.10(307)$ & 0.92 & 0.033 & $F(6,301)=1.72$ & 0.1159 \\
\hline $\begin{array}{l}\text { Independence vs. } \\
\text { Dependence on the teacher }\end{array}$ & 0.010 & 0.04 & $0.22(311)$ & 0.82 & 0.103 & $\mathrm{~F}(6,305)=5.86$ & $0.0000^{* *}$ \\
\hline $\begin{array}{l}\text { Judgment independent of } \\
\text { teacher vs. dependent }\end{array}$ & 0.096 & 0.05 & $1.90(308)$ & 0.05 * & 0.034 & $\mathrm{~F}(6,302)=1.82$ & 0.0954 \\
\hline $\begin{array}{l}\text { Internal criteria vs. } \\
\text { External criteria }\end{array}$ & 0.034 & 0.04 & $0.74(314)$ & 0.46 & 0.238 & $F(6,308)=16.10$ & $0.0000^{* *}$ \\
\hline
\end{tabular}

\section{Conclusions}

The aim of this article was to explore the potential of the ComunicARTE program to promote communicative competence in Spanish language subject of 5th and 6th grade students. Also, its influence on motivational orientation in the classroom is examined. To do so, two schools were observed, an experimental school in which this innovative program was used and a school with a more traditional methodology used as a control group. We must state that, although both schools use a communicative approach to Spanish Language, as required by Spanish legislation, the former focuses more on the development of language skills in significant real settings (promoting the daily interaction of the students) with methodology based on the Framework Teaching for Understanding (Project Zero, Harvard University) [29]. The latter used more activities from a textbook commonly used for teaching the Spanish language.

The results obtained regarding the performance and development of language skills have allowed us to see that:

(1) There is a significant positive differential effect on the oral comprehension variable in the experimental group. We believe this is due to the dynamics produced by ComunicARTE (see Figure A1, Appendix A); every day there is continuous and constant interaction between students, between the teacher and the students and their own personal reflections. These are always real communication situations. The foundations offered by thinking routines [30] appear to have assisted in the structuring and organising of the narrative discourse which is given and received orally. The experimental group works on orality not as an exercise or as textbook activities but as a part of the comprehension tasks proposed in each of the course projects.

(2) There is a significant negative differential effect in the experimental group on the written expression measured by the scaled test in which the students had to tell a story. This point may be explained by the dynamics of the control group. In this group the teachers worked on the writing of narrative text during the whole of Primary 6, given that this is one of the exercises that the Government of Navarra assessment test poses every year. Conversely, with the ad-hoc test data measuring the production of argumentative and instructional texts, there is no evidence of a negative differential effect; on the contrary, it is positive but not significant in favour of the experimental group.

(3) In the remaining language skills (oral expression and written comprehension) no significant differences have been found.

Both results show that the students benefit from the points to which the teachers give greater emphasis and importance. If a great deal of work is done on oral comprehension, as is the case of the experimental group through the interaction of the students, then oral 
comprehension improves. If a great deal of work is carried out on writing stories, then story-writing improves. If the work is done on writing argumentative and instructional texts, then this text type improves.

With regard to the motivational variables, we find that:

(4) There is a significant positive differential effect in the experimental group on the motivational variable, specifically on the subscale of the development of independent judgment. This may be explained by the dynamics created by ComunicARTE as it requires the students to offer continuous feedback and self-assessment, all of which with the assistance of the rubrics. The teacher's intervention on this aspect is minimal. The rubrics used by the students are easy for them to understand and manage, which favours and helps the development of what Claxton calls a 'nose' for quality [31]. They know what is important and what is valuable to produce good work. This allows the students at the experimental school to work independently of the teacher, with prior knowledge of what is good or bad. Considering the age of the students, the development of this capacity is a wonderful advance and benefit which may be attributed to how work is done in the Language class.

Bearing all this in mind, we can say that ComunicARTE, by using the framework Teaching for Understanding [29], cooperative work, reflexive practice with thinking routines, and the rubrics, helps develop the language skills by creating dialogic spaces that promote oral comprehension. As we stated in the introduction, this is one of the prescriptions of the Spanish law on education, which, due to lack of educational material, is not being developed appropriately.

Developing orality and using dialogue in the teaching-learning processes facilitates meaningful learning of knowledge. Managing to make the contents proposed for a subject become relevant and long-lasting for the students means they must have the opportunity to construct and share meanings, to promote communication in the classroom putting knowledge to use and avoiding inert knowledge. As David Perkins said [29], it is more like learning to skate than learning about skating. In this sense, the use of language is fundamental in learning each and every one of the subjects in the syllabus. Varied contents must be acquired from a perspective which pushes us to do so with learning focusing on the student and his/her experience. Therefore, the use of oral language links learning in as much as it allows them to think in a more organised way, to dialogue by expressing thoughts, emotions and experiences; to make critical judgments; to create ideas; to structure knowledge; to make decisions and to enjoy listening. All of which, in addition, contributes to the development of independent judgment.

In the classroom, ComunicARTE allows for progress towards communications which are not merely mono-managed by the teacher and the pupil individually, but plurimanaged, which emphasises communicative interaction and collaboration. On the basis of a dialogic space, new areas of meaning are created as the children listen to each other, ask and offer help and change their perspectives. In this way, the children learn to think: (a) with the responsibility of explaining and justifying their thoughts to others, and (b) by creating new interpretations, sharing other points of view to reaching new meanings. This, in turn, refreshes thought and leads to new interpretations. If the students have the chance to express themselves to their classmates, they demonstrate their own learning and realise that their explanations and thinking promotes the learning of the others.

By creating spaces for dialogue in the classroom, learning does not merely rest on the individual work of the student and the teacher (as does occur in the control group in our study), but on working in collaboration with others, sharing goals and constructing understanding about what the studied content means and how it is projected in the world. The teacher offers guidance and exercises influence to create the conditions to successfully become skilled at interaction for learning [32-34].

Orality has long been disregarded and is often the most overlooked of all the language skills. Improving dialogue in the classroom requires us to work in a specific, determined way. Progress towards a more holistic vision of dialogue in the classroom implies reflection 
on the processes through which it is produced and a thorough study of its methodological repercussions. The process may be blocked or facilitated depending on the type of interaction taken, the number of pupils in the classroom and their distribution, technology [35], the lack of tools or materials available to the students and the feedback between them. ComunicaRTE can be an important contribution in this field. One of the truest values of the ComunicARTE proposal as a dialogic space for the development of students' communicative competence lies more in the manner in which the individual and group work is considered, rather than in the tools (iPads) it uses.

The limitations of this research are the small sample size and the use of convenience sampling. The experimental group was chosen because they wanted to obtain evidence of the potential of the program and the control group because it was more accessible and was interested in research in this field. Regarding these limitations Gall, Borg y Gall [36] p. 228, say 'Researchers often need to select a convenience sample or face the possibility that they will be unable to do the study. Although a sample randomly drawn from a population is more desirable, it usually is better to do a study with a convenience sample than to do no study at all- assuming, of course, that the sample suits the purpose of the study'.

Author Contributions: Data curation, S.L., M.C.G.-T., S.I.-G. and A.Z.; formal analysis, S.L., M.C.G.T., S.I.-G. and A.Z.; funding acquisition, S.L.; investigation, S.L., M.C.G.-T., S.I.-G. and A.Z.; methodology, S.L., M.C.G.-T. and A.Z.; project administration, S.L.; resources, S.L.; software, S.L.; supervision, S.L.; validation, S.L.; visualization, S.L.; writing—original draft, S.L., S.I.-G. and A.Z.; writing—review and editing, S.L., M.C.G.-T., S.I.-G. and A.Z. All authors have read and agreed to the published version of the manuscript.

Funding: This work was supported by the Research Projects of University of Navarra [PIUNA 11-2015 Study of the effectiveness of using a teaching-learning system for Language in Primary that incorporates teaching thinking and cooperative work: cognitive and non-cognitive variables]. Also we got two undergraduate student collaboration grants by Ministry of Education (Spain). The project has been external and positively evaluated by National Assessment and Prospecting Agency (ANEP) within the Ministry of Economy and Competitiveness (Spain). More info: https://goo.gl/ExZ3nO.

Institutional Review Board Statement: The study was conducted according to the guidelines of the Declaration of Helsinki, and approved by the Institutional Review Board (or Ethics Committee) of UNIVERSIDAD DE NAVARRA (protocol code 037/2015 and date of approval 12 September 2016).

Informed Consent Statement: Informed consent was obtained from all subjects involved in the study. Data Availability Statement: Not applicable.

Acknowledgments: We would like to thank the teachers of the two schools studied and the collaboration of their students and families. We also appreciate the help received during the data collection by Concha Iriarte, Álvaro González, Nicolás Muraciole, Fátima Sala, Sheila Martínez, Leyre Laborda, Amaia Medina, Iciar Antoñanzas e Irene Zorrilla.

Conflicts of Interest: The authors declare no conflict of interest. The funders had no role in the design of the study; in the collection, analyses, or interpretation of data; in the writing of the manuscript, or in the decision to publish the results.

\section{Appendix A}

The objective of ComunicARTE is to develop the student's reflexive work, his/her self-regulation and teamwork. To do so, it establishes the framework of Teaching for Understanding [29] as a structure which articulates the design of the whole learning process and aims to offer enough space for personal expression. It brings together various methodologies: techniques and strategies for cooperative learning [37-40] using the potential of social learning to develop understanding; the Theory of Multiple Intelligences [41] attending, on the one hand, to student diversity and, on the other, to the person as a whole; thinking routines which make thinking visible, by introducing, exploring, synthesising and/or organising ideas in order to study them in greater depth [30]; and mind maps [42] with two aims: expressing and capturing the thought on paper, and to be used as an efficient study technique. 


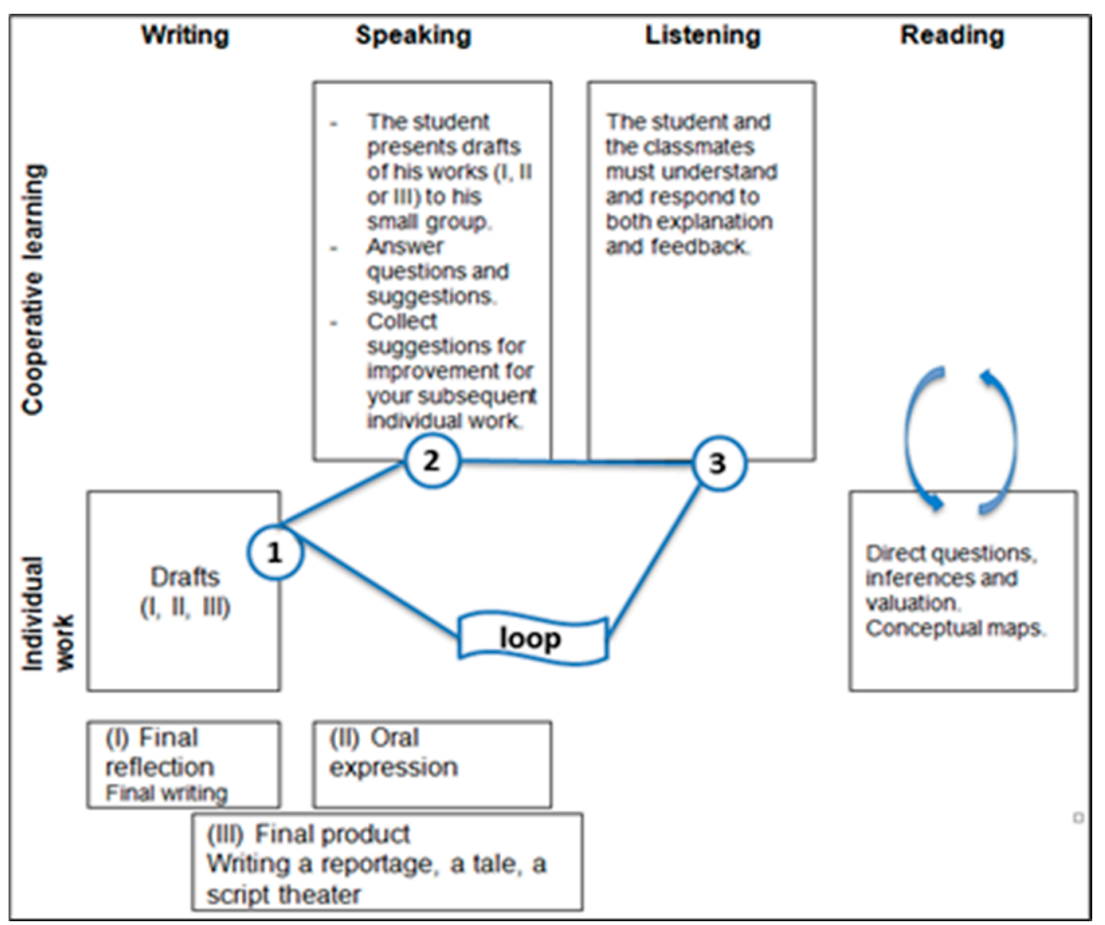

Figure A1. Interaction of the dimensions of language skills in the development of each project.

The ComunicARTE material uses different processes and strategies for working on the four language skills (listening, speaking, reading or writing) from the communicative perspective. In each academic year three projects are carried out. Each of these projects is designed to be worked on over an average period of 2 to 3 months in 40 class sessions. Throughout each project the students work on three different products, all individual, but with the assistance and the constant feedback of classmates. In Figure A1, we show the work process followed for each of the three projects that make up the academic year. These students work individually on their three products, but are constantly helped during the process by their classmates' feedback (dialogic spaces) under the guidance of rubrics. The three products are:

(I). Final reflection. Final essay for personal assessment of the work carried out in the project in which the students describe how they have worked and what they have learned. This is an exercise in metacognition in which they reflect on what they have done.

(II). Oral presentation. The students prepare this during the whole project and improve it with their classmates' comments. It is finally presented to the teacher. The students have a rubric with the quality criteria which is maintained throughout each of the projects.

(III). Final product linked to the content of the project (e.g., writing a report, a story or a script for a play).

We tested the accuracy of its contents with reference to the theory of language teaching [18]. As we have checked it deals appropriately with each of the language skills/strategies which make up the theoretical models for written expression [43], oral expression [44], oral comprehension [45-47] and written comprehension [48-51]. In addition, we found the adaption of its contents to be in consonance with the capacities, motivation and interests of the students.

Specifically, for the development of oral expression, the different strategies of Bygate's model are applied [32]. In this model emphasis is placed on interaction and communicative collaboration, differentiating between the necessary knowledge, such as control of the language system and aspects related with culture, and the skills required to adjust and adapt to communication. Both facets, knowledge and skills, are necessary for successful 
expression. In the program the different micro-skills of the oral expression are applied, these are (see some of them at Figure A2): (1) Planning the discourse, anticipate and prepare the topic and the interaction by analysing the situation and writing the intervention); (2) guiding the discourse, starting the topic and the interaction, developing it and closing it; (3) negotiating the discourse, adapting the level of specification of the oral text or evaluating comprehension during interaction; and (4) producing the text, facilitating production by taking into account the verbal and non-verbal aspects.

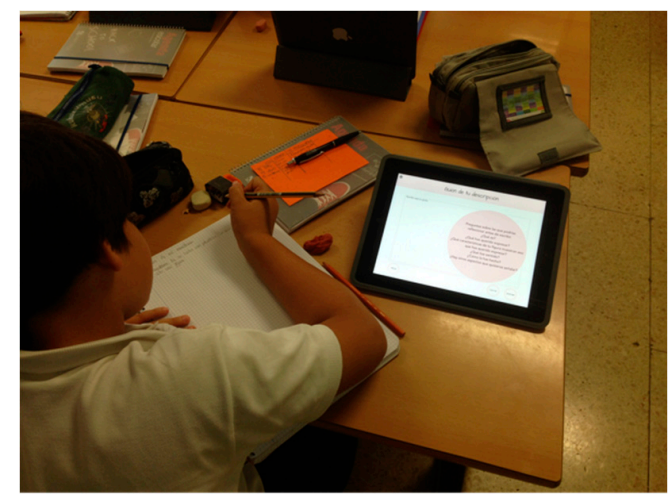

Producing the text

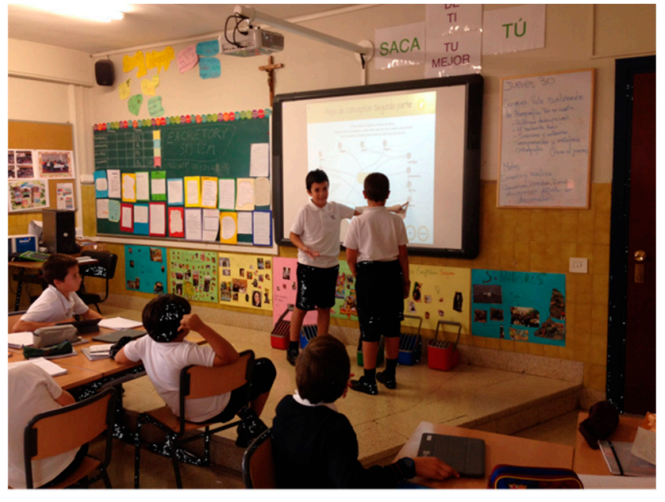

Guiding the discourse

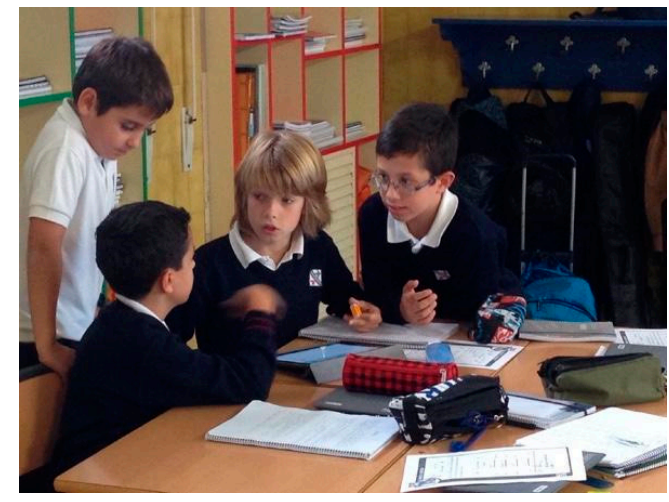

Negotiating meaning

Figure A2. Development of oral expression.

In the development of oral comprehension, the following micro-skills must be highlighted [33-35]: selecting, interpreting, anticipating, inferring and retaining the information (see some of them at Figure A3).

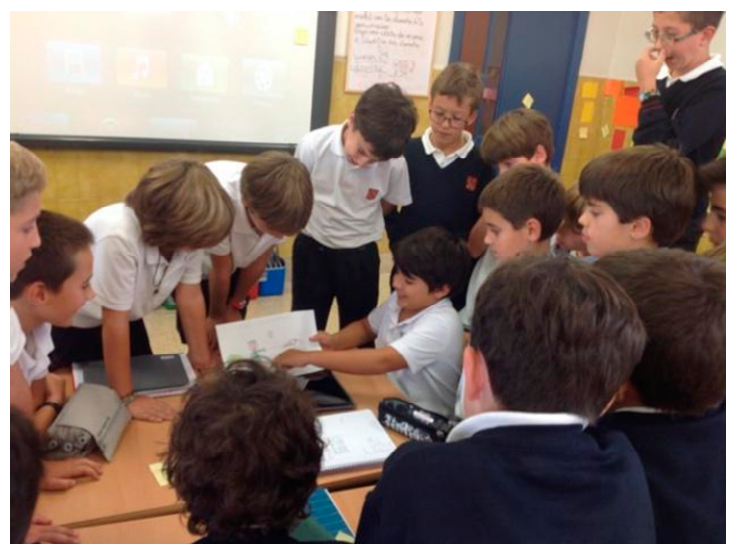

Figure A3. Development of oral comprehension. 
In relation to written expression, the written composition process is followed by these steps: make plans, write and review. Finally in accordance with the model developed [37-40] written comprehension is achieved from the correlation between what is read and what the reader already knows about the subject. The specific skills that are developed from this model may be grouped from the most instrumental to the most comprehensive and reflective (Figure A4). For example, students develop task related with perception, anticipation, inferences, main and secondary ideas, structure and form or auto evaluation.
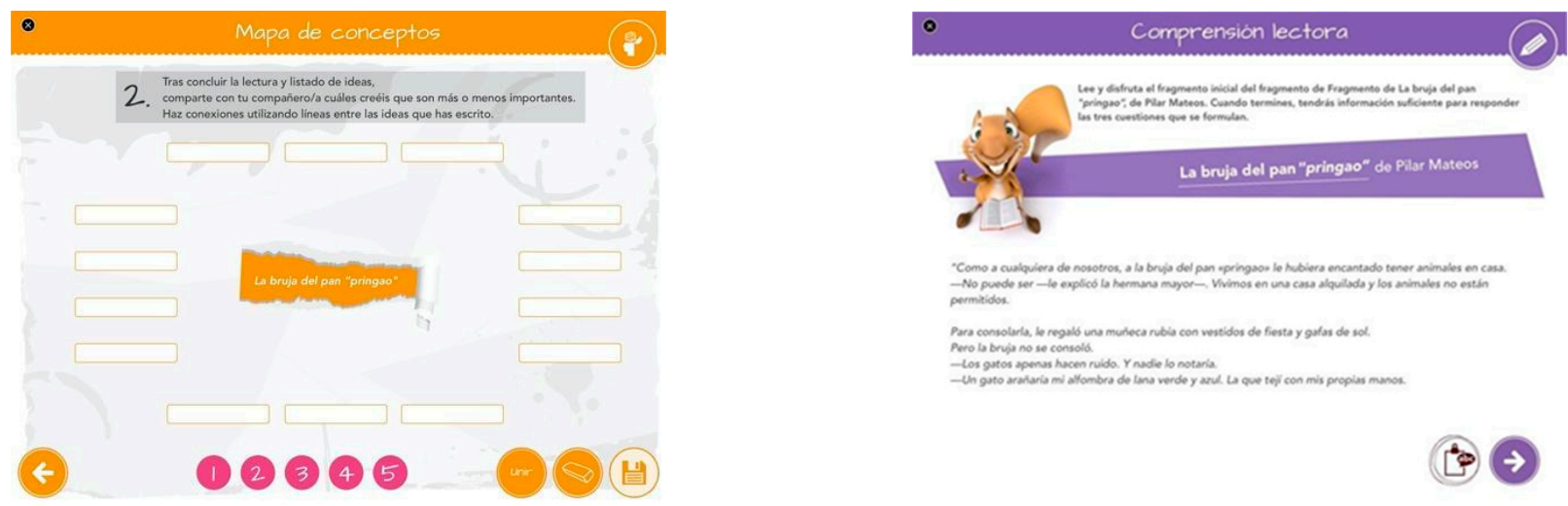

Figure A4. Reading comprehension activities (iPad).

\section{Appendix B}

Table A1. Summary of interaction regression coefficients between POST and Exper (in the scaled and ad-hoc tests) in accordance with the model established: $y_{i}=\beta_{0}+\beta_{1}$ Exper $_{i}+\beta_{2}$ POST $_{i}+\beta_{3}$ POST $_{i} \times$ Exper $_{i}+\beta_{4}$ Lan $_{i}+\beta_{5}$ Lan $_{i}+\beta_{6}$ sex $_{i}+\varepsilon_{i}$.

\begin{tabular}{|c|c|c|c|c|c|c|c|}
\hline & \multicolumn{4}{|c|}{ Coef $\beta_{3}$ POST $_{i} \times$ Exper $_{i}$} & \multicolumn{2}{|l|}{ Model } & \multirow[b]{2}{*}{$P>F$} \\
\hline & 11 Post $\times$ Exper & Std. Err. & $t(g 1)$ & $P>t$ & R-Squared & $\mathbf{F}$ & \\
\hline Oral comprehension (scaled) & 0.1618489 & 0.04 & $3.25(313)$ & $0.00 * *$ & 0.2073 & $\mathrm{~F}(6,307)=3.38$ & $0.0000^{* *}$ \\
\hline Oral comprehension (ad-hoc) & 0.0251007 & 0.02 & $1.12(319)$ & 0.26 & 0.3975 & $\mathrm{~F}(6,312)=34.31$ & $0.0000 * *$ \\
\hline Finding and obtaining info. & 0.0575463 & 0.03 & $1.66(318)$ & 0.09 & 0.1646 & $\mathrm{~F}(6,312)=10.24$ & 0.0000 ** \\
\hline Integration and interpretation & -0.0066522 & 0.03 & $0.23(318)$ & 0.81 & 0.3524 & $\mathrm{~F}(6,312)=28.29$ & 0.0000 ** \\
\hline Reflection and assessment & 0.0713448 & 0.04 & $1.49(318)$ & 0.13 & 0.1140 & $\mathrm{~F}(6,312)=6.69$ & $0.0000^{* *}$ \\
\hline Written Comprehension (scaled) & -0.0522513 & 0.04 & $-1.28(314)$ & 0.20 & 0.4135 & $\mathrm{~F}(6,309)=36.31$ & 0.0000 ** \\
\hline Inferential responses & -0.1252121 & 0.03 & $-0.79(315)$ & 0.43 & 0.3184 & $\mathrm{~F}(6,309)=24.06$ & $0.0000 * *$ \\
\hline Literal responses & -0.0666446 & 0.04 & $-1.53(316)$ & 0.13 & 0.4033 & $\mathrm{~F}(6,310)=34.93$ & $0.0000 * *$ \\
\hline Written Comprehension (ad-hoc) & -0.0100999 & 0.03 & $-0.30(318)$ & 0.76 & 0.4499 & $\mathrm{~F}(6,312)=42.53$ & $0.0000 * *$ \\
\hline Finding and obtaining & -0.0208941 & 0.05 & $-0.41(318)$ & 0.68 & 0.2269 & $\mathrm{~F}(6,312)=15.26$ & 0.0000 ** \\
\hline Integration and interpretation & 0.0056213 & 0.04 & $0.14(318)$ & 0.88 & 0.4631 & $\mathrm{~F}(6,312)=44.85$ & $0.0000 * *$ \\
\hline Reflection and assessment & -0.0266183 & 0.05 & $-0.52(318)$ & 0.60 & 0.1946 & $\mathrm{~F}(6,312)=12.56$ & $0.0000 * *$ \\
\hline Written Expression (scaled) & -0.1791061 & 0.03 & $-5.67(319)$ & $0.00 * *$ & 0.2674 & $F(6,313)=19.04$ & $0.0000 * *$ \\
\hline Coherence-style & -0.2369211 & 0.05 & $-4.72(319)$ & $0.00 * *$ & 0.3085 & $F(6,313)=23.27$ & $0.0000 * *$ \\
\hline Contents & -0.121291 & 0.03 & $-3.47(319)$ & $0.00 * *$ & 0.3625 & $\mathrm{~F}(6,313)=29.67$ & $0.0000^{* *}$ \\
\hline Written Expression (ad-hoc) & 0.029062 & 0.02 & $1.08(317)$ & 0.28 & 0.3242 & $\mathrm{~F}(6,311)=24.86$ & $0.0000 * *$ \\
\hline $\begin{array}{l}\text { Appropriateness } \\
\text { and presentation }\end{array}$ & -0.012612 & 0.02 & $-0.44(323)$ & 0.66 & 0.2289 & $F(6,317)=15.68$ & $0.0000 * *$ \\
\hline Cohesion & 0.0150041 & 0.03 & $0.51(324)$ & 0.61 & 0.2175 & $\mathrm{~F}(6,318)=14.73$ & $0.0000^{* *}$ \\
\hline Coherence & 0.0836467 & 0.04 & $1.85(322)$ & 0.06 & 0.2759 & $\mathrm{~F}(6,316)=20.07$ & $0.0000 * *$ \\
\hline Oral Expression (ad-hoc) & -0.0008048 & 0.03 & $0.02(326)$ & 0.98 & 0.0445 & $\mathrm{~F}(6,320)=2.49$ & $0.0230 *$ \\
\hline Fluency & 0.0141071 & 0.05 & $0.25(329)$ & 0.80 & 0.0713 & $\mathrm{~F}(6,323)=4.13$ & $0.0005^{* *}$ \\
\hline Appropriateness & 0.0225638 & 0.03 & $0.73(329)$ & 0.46 & 0.0290 & $\mathrm{~F}(6,323)=1.61$ & 0.1449 \\
\hline Cohesion & -0.1032492 & 0.05 & $1.84(327)$ & 0.06 & 0.0382 & $\mathrm{~F}(6,321)=2.13$ & 0.0501 * \\
\hline Coherence & 0.0503208 & 0.02 & $1.75(328)$ & 0.08 & 0.1603 & $\mathrm{~F}(6,322)=10.24$ & $0.0000 * *$ \\
\hline
\end{tabular}

${ }^{*} p<0.05,{ }^{* *} p<0.01$. 


\section{References}

1. Council of Europe. Common European Framework of Reference for Languages: Learning, Teaching and Assessment; Council of Europe: Strasbourg, France, 2001.

2. Aragonés, P. Didáctica de la Lengua y la Literatura Para Educar en el s.XXI; La Muralla: Madrid, Spain, 2004.

3. Guerrero, P. Didáctica de la Lengua Castellana y la Literatura; Pirámide: Madrid, Spain, 2015.

4. López, A. Didáctica de la Lengua y la Literatura; DM: Murcia, Spain, 2000.

5. Martín, R. Manual de Didáctica de la Lengua y la Literatura; Síntesis: Madrid, Spain, 2009.

6. Mendoza, A. Didáctica de la Lengua y la Literatura Para Primaria; Pearson Education: Madrid, Spain, 2003.

7. Ruiz, U. Didáctica de la Lengua Castellana y la Literatura; Graó: Barcelona, Spain, 2011.

8. Álvarez, T. Didáctica de la Lengua Para la Formación de Maestros; La Muralla: Madrid, Sapin, 2013.

9. Clarke, P.; Snowling, M.; Truelove, E.; Hulme, C. Ameliorating Children's Reading-Comprehension Difficulties: A Randomized Controlled Trial. Psychol. Sci. 2010, 21, 1106-1116. [CrossRef] [PubMed]

10. Fricke, S.; Bowyer-Crone, C.; Haley, A.; Hulme, C.; Snowling, M. Efficacy of language intervention in the early years. J. Child Psychol. Psychiatry 2013, 54, 280-290. [CrossRef] [PubMed]

11. Lerväg, A.; Hülme, C.; Melby-Lervag, M. Unpicking the developmental relationship between oral language skills and reading comprehension: It's simple but complex. Child Dev. 2017, 89, 1821-1838. [CrossRef] [PubMed]

12. Wegerif, R.; Mercer, N. A dialogical framework for researching peer talk. Lang. Educ. Libr. 1997, 12, 49-64.

13. Hattie, J.; Timperley, H. The power of feedback. Rev. Educ. Res. 2007, 77, 81-112. [CrossRef]

14. Wegerif, R. Towards a dialogic theory of how children learn to think. Think. Skills Creat. 2011, 6, 179-190. [CrossRef]

15. Ajjawi, R.; Boud, D. Examining the nature and effects of feedback dialogue. Assess. Eval. High. Educ. 2018, 43, 1106-1119. [CrossRef]

16. González, A.; Muracciole, N. Developing Communicative Competence in Students in Primary School. In Proceedings of the Project Zero Perspectives: Zeroing in on Learning, Amsterdan, The Netherlands, 1-3 October 2015.

17. Lara, S.; González, Á.; Ibarrola-García, S. Development communicative competence using iPad, cooperative learning and teaching thinking. In Proceedings of the EdMedia: World Conference on Educational Media and Technology, Washington, DC, USA, 20 June 2017.

18. Lara, S.; González-Torres, M.C.; Muracciole, N.; Sobrino, A. Strategies for Applying Formative Assessment with iPad in an Elementary School. In Proceedings of the ED-MEDIA World Conference on Educational Multimedia, Hypermedia and Telecommunications, Vancouver, BC, Canada, 28-30 June 2016.

19. Lara, S.; González-Torres, M.C.; González, A.; Muracciole, N. Presentation and assessment project for the ComunicARTE didactic proposal aimed at promoting thinking and self-regulated learning. In Proceedings of the 17th International Conference of Thinking ICOT, Bilbao, Spain, 29 June-3 July 2015.

20. Lara, S.; González-Torres, M.C.; González, A.; Muracciole, N. ComunicARTE: Developing communicative competences in Primary through teaching thinking and cooperative work. In Proceedings of the ED-MEDIA 2015. World Conference on Educational Multimedia, Hypermedia and Telecommunications, Montreal, QC, Canada, 22 June 2015.

21. Harter, S. A new self-report scale of intrinsic versus extrinsic orientation in the classroom: Motivational and informational components. Dev. Psychol. 1981, 17, 300-312. [CrossRef]

22. Steen-Utheim, A.; Wittek, A.L. Dialogic Feedback and Potentialities for Student Learning. Learn. Cult. Soc. Interact. 2017, 15, 18-30. [CrossRef]

23. Cuetos, F.; Ramos, J.L.; Ruano, E. Proesc. Evaluación de los Procesos de Escritura; TEA: Madrid, Spain, 2004.

24. Cuetos, F.; Rodríguez, E.; Ruano, E.; Arribas, D. Prolec-R. Batería de Evaluación de los Procesos Lectores, Revisada; TEA: Madrid, Spain, 2014.

25. Cuetos, F.; Arribas, D.; Ramos, J.L. Prolec-Se-R. Batería de Evaluación de los Procesos Lectores en Secundaria y Bachillerato, Revisado; TEA: Madrid, Spain, 2016.

26. González-Torres, M.C.; Tourón, J.; Gaviria, J.L. La Orientación Motivacional Intrínseca-Extrínseca en el aula: Validación de un Instrumento. Bordón 1994, 46, 35-51.

27. McCombs, B.L. The Definition and Measurement of Primary Motivational Processes. In Testing and Cognition; Wittrock, M.C., Baker, E.L., Eds.; Prentice Hall: Upper Saddle River, NJ, USA, 1991; pp. 63-81.

28. White, R.W. Motivation reconsidered: The concept of competence. Psychol. Rev. 1959, 66, 297-333. [CrossRef] [PubMed]

29. Blythe, T. The Teaching for Understanding Guide; Jossey-Bass: New York, NY, USA, 1997.

30. Ritchhart, R.; Church, M.; Morrison, K. Making Thinking Visible: How to Promote Engagement, Understanding, and Independence for All Learners; John Wiley \& Sons: New York, NY, USA, 2011.

31. Claxton, G. What's the Point of School? Rediscovering the Heart of Education; Simon and Schuster: New York, NY, USA, 2013.

32. Fisher, D.; Frey, N.; Hattie, J. Teaching Literacy in the Visible Learning Classroom; Corwin: Newbury Park, CA, USA, 2017.

33. Mercer, N.; Dawes, L. Thinking together. Abil. Talk 2016, 18, 1-5.

34. Resnick, L.B.; Schantz, F. Re-thinking intelligence: Schools that build the mind. Eur. J. Educ. 2015, 50, 340-349. [CrossRef]

35. Major, L.; Warwick, P.; Rasmussen, I.; Ludvigsen, S.; Cook, V. Classroom dialogue and digital technologies: A scoping review. Educ. Inf. Technol. 2018, 23, 1995-2028. [CrossRef]

36. Gall, M.D.; Borg, W.R.; Gall, J.P. Educational Research: An Introduction; Longman: White Plains, NY, USA, 1996. 
37. Johnson, D.W.; Johnson, R.T.; Holubec, E.J. The New Circles of Learning: Cooperation in the Classroom and School; ASCD: Alexandria, VA, USA, 1994.

38. Kagan, L.; Kagan, M.; Kagan, S. Learning Structures for Teambuilding; Kagan Publishing: San Clemente, CA, USA, 1997.

39. Kagan, M.; Robertson, L.; Kagan, S. Learning Structures for Classbuilding; Kagan Publishing: San Clemente, CA, USA, 1995.

40. Kagan, S.; Kagan, M. Cooperative Learning; Kagan Publishing: San Clemente, CA, USA, 2009.

41. Gardner, H. Frames of Mind: The Theory of Multiple Intelligences; Basics: New York, NY, USA, 1983.

42. Buzan, T. Modern Mind Mapping for Smarter Thinking; BookBaby: Pennsauken, NJ, USA, 2013.

43. Flower, L.S.; Hayes, J.R. The cognition of discovery: Defining a rhetorical problem. Coll. Compos. Commun. 1980, 31, 21-32. [CrossRef]

44. Bygate, M. Speaking; Oxford University Press: Oxford, UK, 1987.

45. Rivers, W.M.; Temperlay, M.X. A Practical Guide to the Teaching of English as a Second or Foreign Language; Oxford University Press: Oxford, UK, 1978.

46. McDowell, J.; Stevens, S. Basic Listening; E.Arnold: London, UK, 1982.

47. Rixon, S. The design of materials to foster particular linguistic skills. The teaching of listening comprehension. ERIC Doc. Reprod. Serv. No. ED 1981, 258, 465.

48. Cassany, D.; Luna, M.; Sanz, G. Enseñar Lengua, 8th ed.; Graó: Barcelona, Spain, 2002.

49. Alonso, J.; Mateos, M. Comprensión lectora: Modelos, entrenamiento y evaluación. Infancia y Aprendizaje 1985, 31, 5-19. [CrossRef]

50. Colomer, T.; Camps, A. Enseñar a Leer, Enseñar a Comprender; MEC: Madrid, Spain, 1991.

51. Solé, I. Estrategias de Lectura; Graó: Barcelona, Spain, 1992. 